\title{
PEMBINAAN AKHLAK MAHASISWA MELALUI UNIT KEGIATAN MAHASISWA LEMBAGA DAKWAH KAMPUS (STUDI KASUS DI UNIVERSITAS HASANUDDIN MAKASSAR)
}

\author{
oleh: \\ HALIK \\ Dosen Pendidikan Agama Islam di Fakultas Farmasi, Universitas Halu Oleo \\ Email: halikdaengkalla@gmail.com
}

\begin{abstract}
ABSTRAK
Telah dilaksanakan penelitian tentang peranan program kerja Unit Kegiatan Lembaga Dakwah Kampus (UKM LDK) dalam pembinaan akhlak mahasiswa di Universitas Hasanuddin (Unhas) Makassar. Penelitian ini bertujuan mengetahui pelaksanaan program kerja UKM LDK dan peranannya dalam menanamkan nilai-nilai akhlak mulia kepada mahasiswa. Metode penelitian bersifat kualitatif dengan instrumen pengumpulan data berupa observasi, wawancara, angket, dan dokumentasi. Data yang diperoleh selanjutnya diolah dan dianalisis secara induktif serta keabsahan data. Penentuan informan dilakukan secara purposive sampling. Hasil penelitian diperoleh pelaksanaan program kerja UKM LDK merupakan proses pembelajaran yang menggunakan berbagai metode pendidikan Islam. Program kerja UKM LDK dapat mendorong perbaikan akhlak, meningkatkan pemahanan keislaman, dan pembentukan lingkungan belajar yang islami. Disimpulkan bahwa UKM LDK berperan dalam pembinaan akhlak mahasiswa.
\end{abstract}

Kata Kunci: Pembinaan akhlak, Mahasiswa, Lembaga Dakwah Kampus, Program kerja

\section{DEVELOPMENT OF MORAL OF STUDENTS THROUGH ACTIVITIES OF UNIT KEGIATAN MAHASISWA LEMBAGA DAKWAH KAMPUS (CASE STUDY IN HASANUDDIN UNIVERSITY MAKASSAR)}

The research has been carried out on the role of the work program of the Unit Kegiatan Lembaga Dakwah Kampus (UKM LDK) in the moral development of students at the University of Hasanuddin (Unhas) Makassar. This study aims to determine the implementation of the UKM LDK work program and its role in instilling noble moral values for students. The research method is qualitative with data collection instruments in the form of observations, interviews, questionnaires, and documentation. The data obtained is then processed and analyzed inductively and the validity of the data. Determination of informants is done by purposive sampling. The results of the study obtained the implementation of the LDK UKM work program is a learning process that uses various methods of Islamic education. The LDK UKM work program can encourage moral improvement, increase Islamic understanding, and establish an Islamic learning environment. It was concluded that UKM LDK played a role in student moral development.

Keywords: Moral coaching, Students, Campus Da'wah Institution, Work Program 


\section{PENDAHULUAN}

Membentuk individu berakhlak mulia merupakan salah satu tujuan pendidikan nasional yang diamanatkan dalam Undang-Undang Nomor 20 Tahun 2003, tentang Sistem Pendidikan Nasional. Pendidikan di Indonesia bertujuan mengembangkan potensi peserta didik agar menjadi manusia yang beriman dan bertakwa kepada Tuhan Yang Maha Esa, berakhlak mulia, cakap, kreatif, mandiri, dan menjadi warga negara yang bertanggung jawab. (Dirjen Pendis, 2007)

Pencapaian kualitas kelulusan berdasarkan kompetensi akademik saja belum cukup. Individu yang berkompeten tetapi bermoral rendah, akan merusak sistem tatanan masyarakat. Perguruan tinggi merupakan lembaga yang berkompeten melaksanakan perubahan perilaku individu melalui pembinaan akhlak mulia.

Menurut Azyumardi Azra, pentingnya pendidikan akhlak di perguruan tinggi terkait dengan berkembangnya pandangan masyarakat bahwa perguruan tinggi telah gagal membentuk peserta didik yang memiliki akhlak, moral, dan budi pekerti yang baik. (Zuriah, 2008) Banyaknya kasus kekerasan atau perkelahian mahasiswa, pengrusakan fasilitas umum, demostrasi yang berujung anarkisme, pergaulan bebas muda-mudi, serta penyalahgunaan narkoba menunjukkan rendahnya kualitas akhlak mahasiswa.

Gejala penyakit sosial seperti hedonisme, apatisme, konsumerisme, dan pragmatisme, juga mulai mewabah di kalangan mahasiswa. Karena itu dibutuhkan pembinaan akhlak untuk membentuk karakter mahasiswa yang berbudi pekerti dan berkepribadian mantap.

Universitas Hasanuddin (Unhas) merupakan universitas terbesar di Indonesia Timur. Suasana kampus religius yang ditandai oleh mahasiswi yang berjilbab rapi dan ramainya kegiatan dakwah Islam. Meskipun di lain pihak sering terjadi perkelahian mahasiswa atau tawuran, demonstrasi atau unjuk rasa yang mengganggu ketertiban lalu lintas, dan pergaulan bebas muda-mudi.

Pendidikan berkarakter mendapat perhatian dari Unhas. Namun pendidikan karakter tidak hanya dipelajari di dalam kelas, melainkan lingkungan sekitar memiliki pengaruh yang kuat. (Anonim, ...) Seseorang disebut berkarakter apabila berhasil menyerap nilai dan keyakinan yang dikehendaki masyarakat, serta digunakan sebagai kekuatan moral dalam hidupnya. (Zuriah, 2008)

Pembinaan akhlak di luar kelas dapat dilaksanakan melalui lingkungan belajar yang islami dan keikutsertaan mahasiswa dalam kegiatan ekstrakurikuler. Hal tersebut sesuai dengan prinsip aliran pendidikan empirisme yang mementingkan stimulasi eksternal berupa pengaruh lingkungan dalam perkembangan manusia. Pengalaman yang diperoleh individu dalam kehidupannya merupakan stimulan yang berasal dari alam bebas atau diciptakan dalam bentuk pendidikan. (Khaeruddin, 2004)

Kegiatan ekstrakurikuler yang bergerak di bidang dakwah Islam 
dilaksanakan oleh Unit Kegiatan Mahasiswa Lembaga Dakwah Kampus (UKM LDK) (Siswohartono, 2005) UKM tersebut bergerak di bidang dakwah kampus dengan objek dakwah seluruh civitas akademika termasuk mahasiswa.

UKM LDK di Unhas dikenal dengan nama Mahasiswa Pecinta Mushalla Universitas Hasanuddin (MPM Unhas). UKM ini terlihat mampu mewarnai kehidupan kampus dan membentuk lingkungan belajar yang islami melalui berbagai kegiatan yang melibatkan seluruh civitas akademika dan masyarakat di sekitar kampus. (Halik, 2018)

Sasaran UKM LDK MPM Unhas adalah terbentuknya lingkungan belajar yang kondusif serta membangun kesadaran dan pemahaman Islam (Tim FSLDKN). Lingkungan belajar yang kondusif akan mendukung pembentukan karakter mahasiswa yang berakhlak mulia. Hal tersebut sejalan dengan tujuan pendidikan, yaitu melahirkan individu yang berakhlak mulia.

Penelitian sebelumnya menunjukkan bahwa UKM LDK MPM Unhas memiliki banyak program kerja yang mendidik dan meningkatkan pemahaman beragama mahasiswa. Karena itu peneliti tertarik untuk meneliti bagaimana program kerja UKM LDK dan serta peranannya dalam pembinaan akhlak mahasiswa di Unhas.

\section{METODE PENELITIAN}

Penelitian kasus dengan metode kualitatif ini dilaksanakan pada MeiDesember 2011 di Universitas Hasanuddin Makassar. Teknik pengumpulan data dilakukan secara triangulasi dan analisis data bersifat induktif. Penentuan informan dilakukan dengan metode purposive dan bersifat snowball sampling. Informan terpilih adalah Wakil Rektor III Bidang Kemahasiswaan dan Alumni, dosen matakuliah PAI, pengurus dan mantan pengurus UKM LDK MPM Unhas, pengurus masjid dan mushallah di dalam dan di sekitar kampus Unhas, dan mahasiswa yang pernah mengikuti kegiatan yang diadakan oleh UKM LDK MPM Unhas.

Instrumen yang digunakan adalah angket terbuka, pedoman wawancara, dan pedoman dokumentasi.

Tahapan penelitian adalah:

1. Persiapan: menyusun item dalam instrumen penelitian.

2. Pelaksanaan penelitian kepustakaan: menghimpun data melalui pengkajian karya- karya ilmiah berupa buku, jurnal, dan tesis hasil penelitian terdahulu yang relevan.

3. Pelaksanaan penelitian lapangan: wawancara terhadap informan, membagikan angket terbuka, observasi di masjid dan mushallah, serta observasi program kerja dengan mengikuti langsung serta telaah dokumen laporan kegiatan. 


\section{HASIL DAN PEMBAHASAN}

\section{Hasil Penelitian}

\begin{tabular}{|c|c|c|}
\hline No & Program Kerja & Tujuan \\
\hline 1 & $\begin{array}{l}\text { Belajar Cerita Bermain } \\
(\mathrm{BCB})\end{array}$ & Mengasah kepekaan sosial \\
\hline 2 & $\begin{array}{l}\text { Bimbingan Belajar } \\
\text { Muslim (BBM) }\end{array}$ & $\begin{array}{l}\text { Mempertajam pemahaman materi perkuliahan dan } \\
\text { menanamkan adab menuntut ilmu }\end{array}$ \\
\hline 3 & Jelajah Ilmu (Jeli) & Mengasah kepekaan sosial \\
\hline 4 & $\begin{array}{l}\text { Kajian Hangat Seputar } \\
\text { Islam (Khass) }\end{array}$ & $\begin{array}{l}\text { Menyikapi dan menanggulangi isu-isu hangat yang } \\
\text { sedang beredar di masyarakat }\end{array}$ \\
\hline 5 & Kajian Jumat (Kamat) & $\begin{array}{l}\text { Memberikan pemahaman ilmu syar'i, mempererat } \\
\text { ukhuwah islamiyah, mentransfer nilai-nilai } \\
\text { keislamanan dan memberikan keteladanan akhlak } \\
\text { mulia. }\end{array}$ \\
\hline 6 & Kakak Asuh & $\begin{array}{l}\text { Membiasakan diri hidup sederhana dan mengasah } \\
\text { kepedulian terhadap sesama. }\end{array}$ \\
\hline 7 & $\begin{array}{l}\text { Kuliah Tujuh Menit } \\
\text { (Kultum) }\end{array}$ & $\begin{array}{l}\text { Menambah pemahaman islam islamiyah dan saling } \\
\text { menasehati dalam kebaikan. }\end{array}$ \\
\hline 8 & Kerja Bakti & $\begin{array}{l}\text { Menjaga kebersihan Masjid Kampus Unhas dan } \\
\text { sekitarnya, memperkuat ukhuwah islamiyah, dan } \\
\text { menciptakan suasana nyaman bagi jamaah masjid }\end{array}$ \\
\hline 9 & MPM Peduli & Pembiasaan \\
\hline 10 & Pembelajaran Tajwid & $\begin{array}{l}\text { Meningkatkan pengetahuan tata cara membaca Al- } \\
\text { Qur'an. }\end{array}$ \\
\hline 11 & $\begin{array}{l}\text { Pembelajaran Bahasa } \\
\text { Arab }\end{array}$ & $\begin{array}{l}\text { Memberikan pembelajaran membaca, menulis, dan } \\
\text { berbicara dalam bahasa Arab. }\end{array}$ \\
\hline 12 & $\begin{array}{l}\text { Pengadaan Buletin } \\
\text { Dakwah }\end{array}$ & $\begin{array}{l}\text { Menyebarkan syiar dakwah dan meningkatkan } \\
\text { pemahaman Islam }\end{array}$ \\
\hline 13 & $\begin{array}{l}\text { Pengadaan Majalah } \\
\text { Dinding Dakwah }\end{array}$ & $\begin{array}{l}\text { Menyebarkan syiar dakwah dan meningkatkan } \\
\text { pemahaman Islam }\end{array}$ \\
\hline 14 & $\begin{array}{l}\text { Pengadaan Pamflet } \\
\text { Dakwah }\end{array}$ & $\begin{array}{l}\text { Menyebarkan syiar dakwah dan meningkatkan } \\
\text { pemahaman Islam }\end{array}$ \\
\hline 15 & Pengelolaan website & $\begin{array}{l}\text { Menyebarkan syiar dakwah dan meningkatkan } \\
\text { pemahaman Islam }\end{array}$ \\
\hline 16 & Perayaan Idul Adha & $\begin{array}{l}\text { menyemarakkan perayaan Idul Adha dan menjalin } \\
\text { silaturrahim dengan masyarakat. }\end{array}$ \\
\hline 17 & Semarak Ramadhan & $\begin{array}{l}\text { meningkatkan iman, ilmu, dan amal shaleh dalam } \\
\text { bulan Ramadhan }\end{array}$ \\
\hline 18 & Seminar dan Bedah Buku & $\begin{array}{l}\text { Meningkatkan pemahaman Islam, membangun } \\
\text { citra positif terhadap dakwah, dan membuka } \\
\text { wawasan terhadap isu-isu nasional dan } \\
\text { perkembangan Islam. }\end{array}$ \\
\hline 19 & SMS Dakwah & $\begin{array}{l}\text { Bertujuan mempererat ukhuwah, menambah } \\
\text { wawasan keislaman, dan menguatkan kondisi }\end{array}$ \\
\hline
\end{tabular}




\begin{tabular}{|c|c|c|}
\hline & & ruhiyah pengurus dan anggota LDK \\
\hline 20 & Siaran Islam MPM & $\begin{array}{l}\text { menyebarkan syiar dan menambah wawasan } \\
\text { keislaman melalui media elektronik atau radio }\end{array}$ \\
\hline 21 & $\begin{array}{l}\text { Studi al-Quran Intensif } \\
\text { (Sains) }\end{array}$ & $\begin{array}{l}\text { Memberantas buta aksara Al-Qur'an, memberikan } \\
\text { pembelajaran membaca Al-Qur'an dengan baik } \\
\text { dan benar, dan memberikan pembinaan serta } \\
\text { penanaman nilai-nilai Islam secara utuh }\end{array}$ \\
\hline 22 & Studi Islam Intensif (SII) & $\begin{array}{l}\text { Mempersiapkan kader-kader dakwah yang } \\
\text { tangguh, berjiwa militan, dan profesional. }\end{array}$ \\
\hline 23 & Taklim & $\begin{array}{l}\text { Menambah pemahaman ilmu syariat sesuai } \\
\text { pemahaman ahlus sunnah wal jamaah. }\end{array}$ \\
\hline 24 & $\begin{array}{l}\text { Temu Keluarga Adik } \\
\text { Asuh (Telaga) }\end{array}$ & Mengasah kepekaan sosial \\
\hline
\end{tabular}

\section{Pembahasan}

Pembinaan akhlak yang dilakukan melalui program kerja LDK MPM diuraikan sebagai berikut:

\section{Pembinaan Akhlak Mahasiswa Terhadap Allah Swt.}

Akhlak terhadap Allah Swt. merupakan akhlak yang paling utama yang harus dipegang oleh seorang muslim dan mendasari akhlak terhadap makhluk lain ciptaan-Nya. Namun kebanyakan orang tidak memperhatikan akhlak terhadap Allah Swt. karena beranggapan bahwa prilaku manusia hanya dilihat dalam hubungannya dengan sesama dan lingkungan sekitarnya. Akhlak kepada Allah Swt meliputi cinta, husnuzhan, ikhlas, khauf, qanaa'ah, raja', ridha, syukur, taat, takwa, taubat, dan tawakkal.

Pembinaan akhlak mahasiswa berupa akhlak kepada Allah dilakukan oleh LDK MPM melalui programprogram kajian dan diskusi seperti Kajian Jumat (Kamat), Kuliah Tujuh Menit (Kultum), (Khass), majelis taklim, dan Studi al-Qur'an Intensif (Sains). Setiap sesi program selalu disisipkan ajakan untuk senantiasa mendekatkan diri kepada Allah.
Program lainnya adalah pengadaan Pamflet Dakwah yang berisi tausiyah dan ajakan untuk selalu mendekatkan diri kepada Allah. Demikian pula dengan majalah dinding (mading), Buletin al-Muwahhid, dan website www.ldkmpmuh. org di dalamnya terhadapat materi-materi ketauhidan baik berupa tauhid rububiiyah, tauhid uluhiiyah, dan tauhid asma' wa al-sifaah.

Secara khusus pembinaan sikap husnuzhaan, raja', ridha, dan tawakkal ditanamkan melalui kegiatan Bimbingan Belajar Mahasiswa (BBM). Para peserta dibimbing untuk berpikiran positif terhadap ketentuan Allah dan optimis terhadap janji Allah bagi hamba-Nya yang bersungguh-sungguh dalam menuntut ilmu. Peserta juga dibimbing agar hanya bergantung dan berharap kepada Allah dan berserah diri sepenuhnya atas segala keputusan Allah, dalam hal ini hasil ujian peserta kelak. Apapun hasil ujian yang diperoleh, hendaknya diterima dengan lapang dada sebagai pemberian dari Allah atas usaha yang telah dikerjakan.

Sikap qana'ah dan syukur dapat ditanamkan melalui program MPM Peduli dan Temu Keluarga Adik Asuh 
(Telaga). Program terebut mengajarkan pentingnya berbagi dengan masyarakat yang kurang mampu. Sehingga mahasiswa diharapkan dapat mengambil hikmah berupa rasa syukur atas kecukupan rizki yang diberikan oleh Allah.

\section{Pembinaan Akhlak Mahasiswa Terhadap Rasulullah Saw.}

Akhlak terhadap Rasulullah saw. merupakan konsekuensi dari Akhlak kepada Allah. Rasulullah saw. adalah utusan Allah yang menyampaikan pesan-pesan Allah kepada umat manusia. Akhlak tersebut dimulai dengan beriman kepada Rasulullah saw. Kemudian mencintai dan memuliakannya, taat dan patuh kepadanya, mengucapkan salam dan shalawat kepadanya, serta meneladaninya dalam kehidupan seharihari.

Meneladani kehidupan Rasulullah ditanamkan oleh LDK ini melalui media cetak berupa pamflet dakwah yang berisi hadist-hadist Nabi dan buletin Muwahhid. Diharapkan mahasiswa yang membaca media tersebut memperoleh ilmu pengetahuan tentang kehidupan Rasulullah kemudian tergerak untuk meneladaninya.

Menurut penulis keikutsertaan mahasiswa dalam LDK ini terutama dalam kepanitiaan terlebih lagi dalam kepengurusan, merupakan sarana untuk belajar bagaimana meneladani sifat-sifat Rasulullah yaitu:

\section{a. Shiddiiq (jujur).}

Mahasiswa belajar untuk selalu jujur dalam perkataan dan prilakunya serta berusaha menghindari yang sebaliknya yaitu dusta dan munafik dalam pergaulan sehari-hari. Sifat jujur tercermin dalam sikap para pengurus LDK MPM dalam mengelola LDK ini, misalnya dalam pengelolaan dana yang transparan. Hal tersebut dibuktikan dengan kepercayaan yang berikan oleh pimpinan kampus kepada mahasiswa tersebut untuk mengelola UKM LDK di Unhas diantara banyak LDK lainnya di Unhas.

b. Amaanah (dapat dipercaya).

Mahasiswa belajar bersikap amanah dalam perkataan dan perbuatan seperti memutuskan perkara, menerima dan melaksanakan tugas yang dibebankan kepadanya, serta berusaha menghindari yang sebaliknya yaitu mengkhianati amanah yang diberikan. Sifat amanah tercermin dalam loyalitas para pengurus LDK MPM dalam menjalankah amanah kepemimpinan dan kepanitiaan yang dibebankan kepadanya.

c. Tabliig (menyampaikan).

Mahasiswa belajar menyampaikan dakwah Islam dan mengaplikasikan ilmu yang telah diperoleh kepada civitas akademika dan masyarakat. Hal tersebut dibuktikan dengan kemampuan pengurus LDK MPM bertindak sebagai pemateri dalam program Kultum yang tidak hanya diikuti oleh mahasiswa, melainkan juga oleh civitas akademika lainnya seperti dosen dan karyawan. Sifat Tabliig juga tercermin dalam peran para pengurus LDK MPM sebagai murabbi dalam program Sains dan SII, sebagai pementor bagi Adik Asuh dalam program BCB, dan sebagai pementor bagi mahasiswa dalam program BBM.

d. Fathaanah (cerdas atau pandai). 
Mahasiswa belajar untuk selalu berpikir rasional dalam menghadapi persoalan melalui berbagai tugas dakwah yang berat dan penuh tantangan yang dibebankan kepadanya. Sifat ini tercermin dari semangat pada pengurus LDK MPM untuk terus belajar terutama pada persoalan-persoalan agama dengan cara bertanya kepada pihak yang berkompeten. Dalam mengemban tugas kepemimpinan atau kepanitiaan, mereka terus memperbaiki diri dan memperkuat ruhiyah dengan mempelajari ilmu-ilmu syar'i. Pengurus LDK MPM juga memiliki semangat yang tinggi untuk menuntut ilmu melalui berbagai kegiatan pelatihan, baik yang diadakan oleh LDK ini maupun oleh lembaga dakwah lainnya.

Selain sifat tersebut di atas, Rasulullah juga bersifat ma'shum yaitu tidak pernah berbuat dosa atau maksiat kepada Allah. Mahasiswa dapat belajar untuk menghindari dosa dan kemaksiatan melalui LDK ini. Lingkungan pergaulan yang islami dapat serta kegiatan keagamaan yang padat dan kontinyu yang diadakan LDK MPM, tentu dapat mengisi waktu luang mahasiswa. Kesibukan tersebut dapat menghindarkan mahasiswa dari kegiatan yang tidak bermanfaat.

Meneladani sifat-sifat Rasulullah bukan merupakan hal mudah dan membutuhkan proses yang panjang. Sifat-sifat tersebut diharapkan terus terbawa dalam kehidupan mahasiswa bahkan setelah meninggalkan kampus dan berkarya di tengah masyarakat.

\section{Pembinaan Akhlak Mahasiswa terhadap Diri Sendiri}

Islam mengajarkan setiap muslim untuk memperlakukan dirinya di hadapan Allah dan manusia berdasarkan akhlak yang baik. Beberapa akhlak mulia yang harus dimiliki oleh seorang muslim antara lain berpikir positif, disiplin, iffah, ikhlas, istiqamah, jihad, malu, pemaaf, percaya diri, sabar, setia, tawadhu, tekun, teliti, ulet, dan zuhud.

Berpikir positif, optimis, jihad (bersungguh-sungguh), percaya diri, tekun, dan ulet ditanamkan melalui program Bimbingan Belajar Muslim (BBM). Pementor juga dapat menanamkan akhlaq al-kari>mah terhadap peserta, meliputi adab dalam menuntut ilmu, adab seorang mahasiswa ketika belajar, dan bagaimana menghadapi ujian.

Jihad juga ditanamkan dalam proses kaderisasi pengurus LDK ini yaitu bersungguh-sungguh menjalankan semua amanah yang diberikan misalnya tugas-tugas dalam kepanitiaan dan jabatan dalam kepengurusan. Mahasiswa belajar untuk ikhlas dan menjalankan amanah semata-mata karena Allah demi tegaknya dakwah Islam di kampus Unhas.

Pembinaan sikap disiplin dapat
ditanamkan melalui program
Pembelajaran Bahasa Arab,
Pembelajaran Tajwid, dan Sains. Para
peserta program tersebut diberi motivasi
agar disiplin dalam menuntut ilmu
dengan cara berusaha hadir tepat waktu
dan mengikuti semua sesi pembelajaran.

Berdasarkan observasi penulis, program pembelajaran tersebut senantiasa dimulai tepat waktu. Demikian pula para pesertanya, menampakkan semangat disiplin dan gairah menuntut ilmu. Kalaupun ada peserta yang berhalangan hadir, hal tersebut disebabkan oleh jadwalnya yang bertepatan dengan kuliah atau praktikum mereka. 
Pembinaan sikap tawadhu dan zuhud dapat dilakukan melalui program-program yang dilakukan oleh Biro Adik Asuh dan program Bakti Sosial MPM Peduli. Program ini mengajarkan mahasiswa untuk menjauhi sifat berlebih-lebihan, mengikuti nafsu hedonis, serta meningkatkan rasa tawadhu dan kepedulian nasib umat.

Berdasarkan observasi penulis, para pengurus LDK ini senantiasa bersikap tawadhu dan berprilaku zuhud terhadap dunia. Hal tersebut tercermin dalam penampilan mereka yang berbeda dengan mahasiswa lainnya, yaitu berpenampilan modern dengan gaya mengikuti trend atau mode terbaru. Sementara pengurus LDK ini berpenampilan yang wajar sesuai kebutuhannya sebagai mahasiswa.

Semua program kerja yang dilaksanakan oleh LDK ini dapat membentuk akhlaq al-kariimah mahasiswa sebagai panutan masyarakat kampus. Pengurus UKM ini adalah penyeru dakwah atau dai dalam lingkup dan di sekitar kampus Unhas. Seorang dai harus menampakkan akhlaq alkariimah dalam penampilan dan seluruh prilakunya. Akhlak tersebut merupakan pengaruh ilmu dan ibadahnya.

Mahasiswa yang terlibat dalam kegiatan LDK ini terutama para pengurus akan memperoleh pengalaman dan latihan. Pengalaman merupakan media pembelajaran. Organisasi dalam hal ini LDK MPM memberikan pengalaman berupa sikap, nilai, keterampilan, dan kebiasaan hidup islami bagi mahasiswa.

\section{Pembinaan Akhlak Mahasiwa dalam Bermasyarakat}

a. Berpihak kepada orang yang lemah.

Orang yang lemah adalah masyarakat yang kekurangan baik dari segi fisik, ekonomi, iman, ilmu, maupun kasih sayang. Islam menganjurkan orangorang yang kuat atau memiliki kelebihan dan agar memperhatikan dan membantu orang-orang yang lemah. Sebagaimana firman Allah dalam Q.S. al-Zaariyat/51 19 yang terjemahannya sebagai berikut:

"Dan pada harta-harta mereka ada hak untuk orang miskin yang meminta dan orang miskin yang tidak mendapat bagian".

Efek buruk globalisasi teknologi infomasi mempengaruhi corak bepikir dan pola kehidupan mahasiswa yaitu mengikuti suguhan informasi produkproduk kapitalis yang menjanjikan kesenagan duniawi atau hedonisme. Terlenanya mahasiswa dengan kesenangan pribadi seringkali membuatnya lupa akan kondisi sosial masyarakat di sekitarnya.

Pembinaan sikap keberpikahan terhadap masyarakat lemah dilakukan melalui program Bakti Sosial MPM Peduli. Program tersebut mengajak mahasiswa untuk berbagi dan peduli dengan masyarakat kurang mampu. Selain itu program Kakak Asuh mengajarkan mahasiswa untuk berbagi anak-anak dari masyarakat lemah dengan memberikan bantuan dana pendidikan bagi Adik Asuh. Program Belajar-Cerita-Bermain (BCB) dan Temu Keluarga Adik Asuh (Telaga) mengajarkan mahasiswa berbagi ilmu dan kasih sayang. Penulis melihat antusiasme yang besar dari mahasiswa melalui keterlibatannya. 
Program-program tersebut mampu membangun sensitivitas mahasiswa terhadap kondisi sosial masyarakat. Juga mengikis gejala penyakit sosial yang mulai menghinggapi mahasiswa seperti hedonisme, konsumerisme, dan apatisme. Juga membantu pembentukan karakter mahasiswa sebagai agent of social change yang berpihak kepada kondisi masyarakat yang mayoritas berada di garis kemiskinan.

b. Pergaulan dengan Lawan Jenis

Lawan jenis adalah orang-orang yang memiliki jenis kelamin berbeda satu sama lainnya. LDK MPM menanamkan pentingnya menjaga pergaulan dengan lawan jenis melalui pengalaman bagaimana menjaga pergaulan sesuai dengan firman Allah dalam Q.S. alAhzab/33 yang terjemahannya sebagai berikut:

\section{"Dan apabila kamu meminta sesuatu (keperluan) kepada mereka (isteri- isteri Nabi), maka mintalah dari belakang tabir. Cara yang demikian itu lebih suci bagi hatimu dan hati mereka”.}

Berdasarkan observasi penulis, setiap kegiatan LDK MPM senantiasa terhindar dari ikhtilaat atau bercampur baur antara putra dan putri. Semua kegiatan dilaksanakan terpisah baik oleh tirai pembatas maupun diadakan oleh ikhwan dan akhawaat secara mandiri (berbeda waktu, tempat, dan kepanitiaan).

Kepengurusan LDK ini juga terpisah antara pengurus putra dan putri, sehingga meminimalkan komunikasi di antara mereka. Komunikasi yang minim akan mencegah pengurus LDK MPM dari berdua-duaan (ikhtilaat) antara pengurus putra dan putri karena urusan organisasi, bercampur baur (khalwat) dalam seremonial kegiatannya, dan berjabat tangan.

5. Pembinaan Akhlak Mahasiswa
Terhadap Lingkungan

Lingkungan adalah segala sesuatu yang berada di sekitar manusia. Akhlak terhadap lingkungan yang diajarkan dalam al-Qur'an bersumber dari fungsi manusia sebagai khalifah di muka bumi. Hal tersebut menuntut adanya interaksi manusia dengan sesamanya dan manusia dengan alam sekitarnya. Khalifah berati pengayom, pemelihara, pembimbing, agar manusia senantiasa mencapai tujuan penciptaannya di muka bumi.

Pembinaan akhlak mahasiswa terhadap lingkungan dilakukan melalui program Kerja Bakti. Program tersebut mengajarkan mahasiswa untuk peduli terhadap kebersihan dan keindahan lingkungan Masjid Kampus dan sekitarnya. Penulis melihat suasana yang asri di lingkungan Masjid Kampus, tentunya tidak lepas dari program Kerja Bakti. Demikian pula suasana di Mushallah MPM yang bersih, nyaman, dan teratur, merupakan upaya yang dilakukan oleh LDK MPM dalam pembinaan akhlak mahasiswa terhadap lingkungan.

\section{KESIMPULAN}

Program kerja UKM LDK berperan pembinaan akhlak mahasiswa di Unhas. 


\section{DAFTAR PUSTAKA}

Direktorat Perguruan Tinggi Agama Islam. 2003. Pelaksanaan Pendidikan Agama Islam di Perguruan Tinggi Umum, Jakarta: Departemen Agama Republik Indonesia.

Direktorat Jenderal Pendidikan Islam. 2007. Undang-Undang Nomor 20 Tahun 2003 Tentang Sistem Pendidikan Nasional, Jakarta: Departemen Agama Republik Indonesia

Khaeruddin. 2004. Ilmu Pendidikan Islam, Edisi I. Makassar: Yayasan Fathiya.

Nahlawi, A. 1992. Prinsip-prinsip dan Metoda Pendidikan Islam dalam Keluarga, di Sekolah, dan di Masyarakat. Bandung: Diponegoro Press.

Siswohartono, J. 2005. Tanggung Jawab Perguruan Tinggi dalam Membentuk Manusia Beretika, Forum Kependidikan, Vol. 24, No. 2, Edisi Maret 2005. Palembang: FKIP Universitas Sriwijaya.

Zuriah, Nurul. 2008. Pendidikan Moral dan Budi Pekerti dalam Perspektif Perubahan; Menggagas Platform Pendidikan Budi Pekerti Secara Kontekstual dan Futuristik, Cet II. Jakarta: Bumi Aksara, 2008 